\title{
A Multi-Inductor H Bridge Fault Current Limiter
}

\author{
Amir Heidary ${ }^{1}{ }^{1}$, Hamid Radmanesh ${ }^{2}$, Ali Moghim ${ }^{1}$, Kamran Ghorbanyan ${ }^{1}$, \\ Kumars Rouzbehi ${ }^{3}$, Eduardo M. G. Rodrigues ${ }^{4, *}$ and Edris Pouresmaeil ${ }^{5, *}$ (D) \\ 1 Electrical Engineering Department, Amirkabir University of Technology, 15875-4413 Tehran, Iran \\ 2 Electrical Engineering Department, Aeronautical University of Science and Technology, 15914 Tehran, Iran \\ 3 Department of System Engineering and Automatic Control, University of Seville, 41004 Seville, Spain \\ 4 Management and Production Technologies of Northern Aveiro-ESAN, Estrada do Cercal 449, Santiago de \\ Riba-Ul, 3720-509 Oliveira de Azeméis, Portugal \\ 5 Department of Electrical Engineering and Automation, Aalto University, 02150 Espoo, Finland \\ * Correspondence: emgrodrigues@ua.pt (E.M.G.R.); edris.pouresmaeil@aalto.fi (E.P.); \\ Tel.: +358-505-984-479 (E.P.)
}

Received: 18 May 2019; Accepted: 12 July 2019; Published: 16 July 2019

\begin{abstract}
Current power systems will suffer from increasing pressure as a result of an upsurge in demand and will experience an ever-growing penetration of distributed power generation, which are factors that will contribute to a higher of incidence fault current levels. Fault current limiters (FCLs) are key power electronic devices. They are able to limit the prospective fault current without completely disconnecting in cases in which a fault occurs, for instance, in a power transmission grid. This paper proposes a new type of FCL capable of fault current limiting in two steps. In this way, the FCLs' power electronic switches experience significantly less stress and their overall performance will significantly increase. The proposed device is essentially a controllable $\mathrm{H}$ bridge type fault current limiter (HBFCL) that is comprised of two variable inductances, which operate to reduce current of main switch in the first stage of current limiting. In the next step, the main switch can limit the fault current while it becomes open. Simulation studies are carried out using MATLAB and its prototype setup is built and tested. The comparison of experimental and simulation results indicates that the proposed HBFCL is a promising solution to address protection issues.
\end{abstract}

Keywords: fault current limiter; microgrid protection; power quality; fault current; $\mathrm{H}$ bridge

\section{Introduction}

The immense global growth in energy demand will require additional power generation as well as an efficient, reliable complex meshed power distribution. The existing power grids will experience, in the near future, a growing burden due to an upsurge in electricity demand and will experience an ever-growing penetration of distributed power generation, which are factors that will contribute to a higher incidence of fault current levels. The massive growth of gird interconnection and integration of distributed generators (DGs) increase the network fault current level [1-4]. The solid-state fault current limiter (FCL) is a fast protection device that includes a DC reactor and solid-state switches [1-4]. The voltage source converters (VSCs) of HVDC systems are sensitive to the fault current. Recently, they have been combined with appropriate FCLs to protect them $[5,6]$. There are other types of FCLs that have been introduced in the literature. A resistive superconductor FCL based on variable resistance, which is very complex and costly, has been presented in the works of $[7,8]$. The bridge type FCLs based on DC reactor have been studied in the literature [9-12]. The AC/DC reactor based FCL has been presented in the work of [13]. In this FCL, two-stage operation decreases the voltage stress on the solid-state switches. The other well-known FCL type are the resonance type FCLs, which have high transient voltage, and this is their most important challenge [14,15]. A series two-stage FCL 
that behaves by operation of the solid-state switch in the secondary winding is introduced in the works of $[16,17]$. Saturated core FCL based on DC bias saturation and the series coil is studied in the literature [18-24]. In this type, the electronic switch connects to DC saturation current and does not have any conflict with the line current. Superconductive FCLs have been investigated for limiting the fault current in the microgrid $[25,26]$. FCLs can preserve microgrid from AC grid fault currents because the AC/DC microgrid should be protected in both the AC and DC sides [27]. Novel types of magnetic based FCLs are analyzed in the works of $[28,29]$ to improve the performance of FCL for a power grid. Flux coupled FCLs and bridge type solid-state FCLs [30,31] are used to design a novel H bridge type fault current limiter (HBFCL).

The rest of this paper is organized as follows. In Section 2, the HBFCL structure is presented. In Section 3, the analytical studies are given and, in the next section, the simulation results of the proposed HBFCL are presented. In Section 5, the experimental test results are presented and, finally, the conclusion is drawn.

\section{Proposed HBFCL Configuration}

The proposed HBFCL is connected in series with the line to protect the point of common coupling (PCC) of the microgrid against the fault current. The HBFCL includes four inductors, $L_{1}-L_{4}$, as shown in Figure 1. An antiparallel power electronic IGBTs, that is, $G_{1}$ and $G_{2}$, are connected as main switches to the middle branch of the $\mathrm{H}$ bridge. $L_{3}$ and $L_{4}$ are coupled with $L_{5}$ and $L_{6}$, respectively. The power electronic switch, $G_{3}$ and $G_{4}$, and rectifier diodes, $D_{1}-D_{4}$, are connected to these coupled inductances. After switching of IGBT switches $\left(G_{3}\right.$ and $\left.G_{4}\right), L_{5}$ and $L_{6}$ are bypassed and two levels for $L_{3}$ and $L_{4}$ in the different modes are configured.

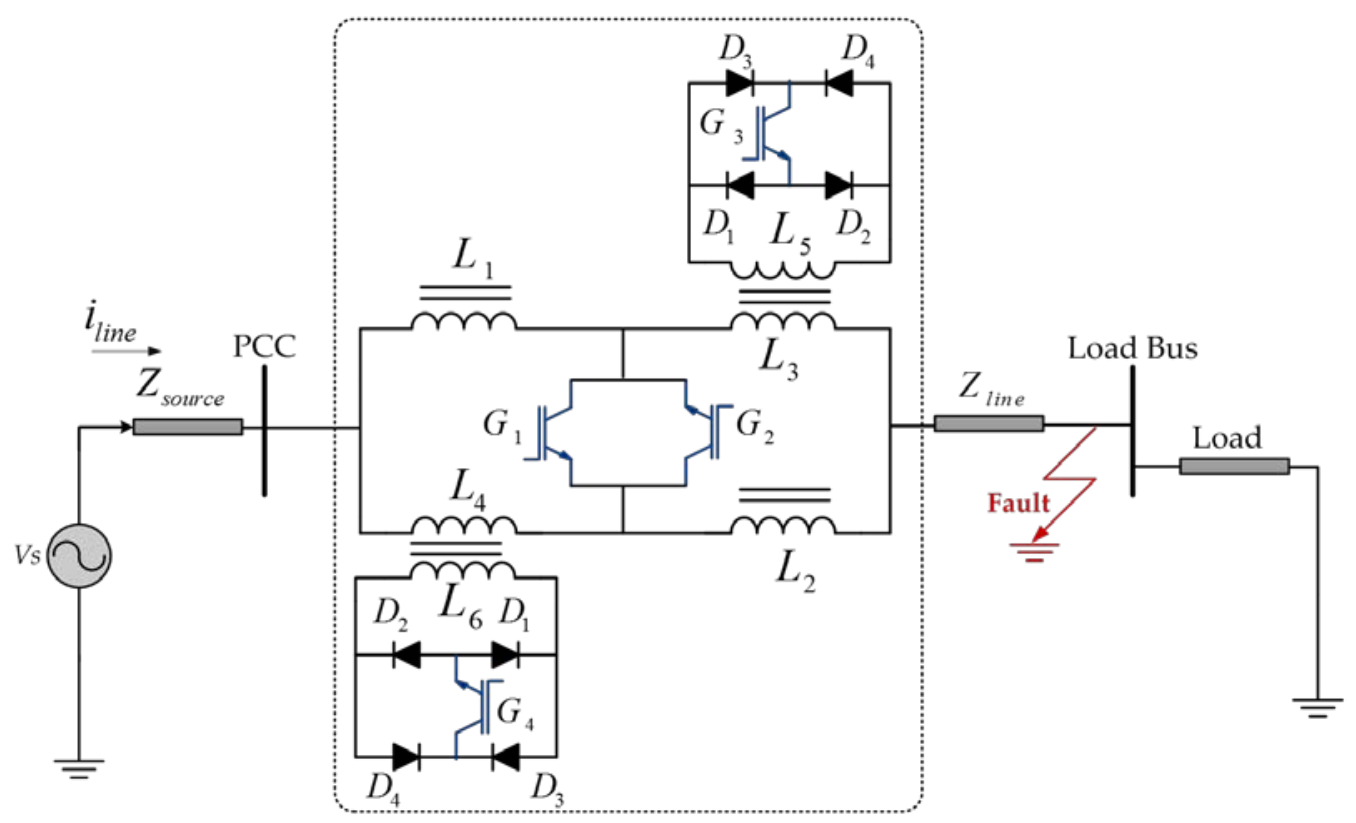

Figure 1. Proposed H bridge type fault current limiter (HBFCL) topology.

The operation of the proposed FCL is divided into three modes, as shown in Figure 2. Figure 2a-c show the HBFCL equivalent circuit during the normal operation mode after fault occurrences and during the fault limiting mode, respectively. 

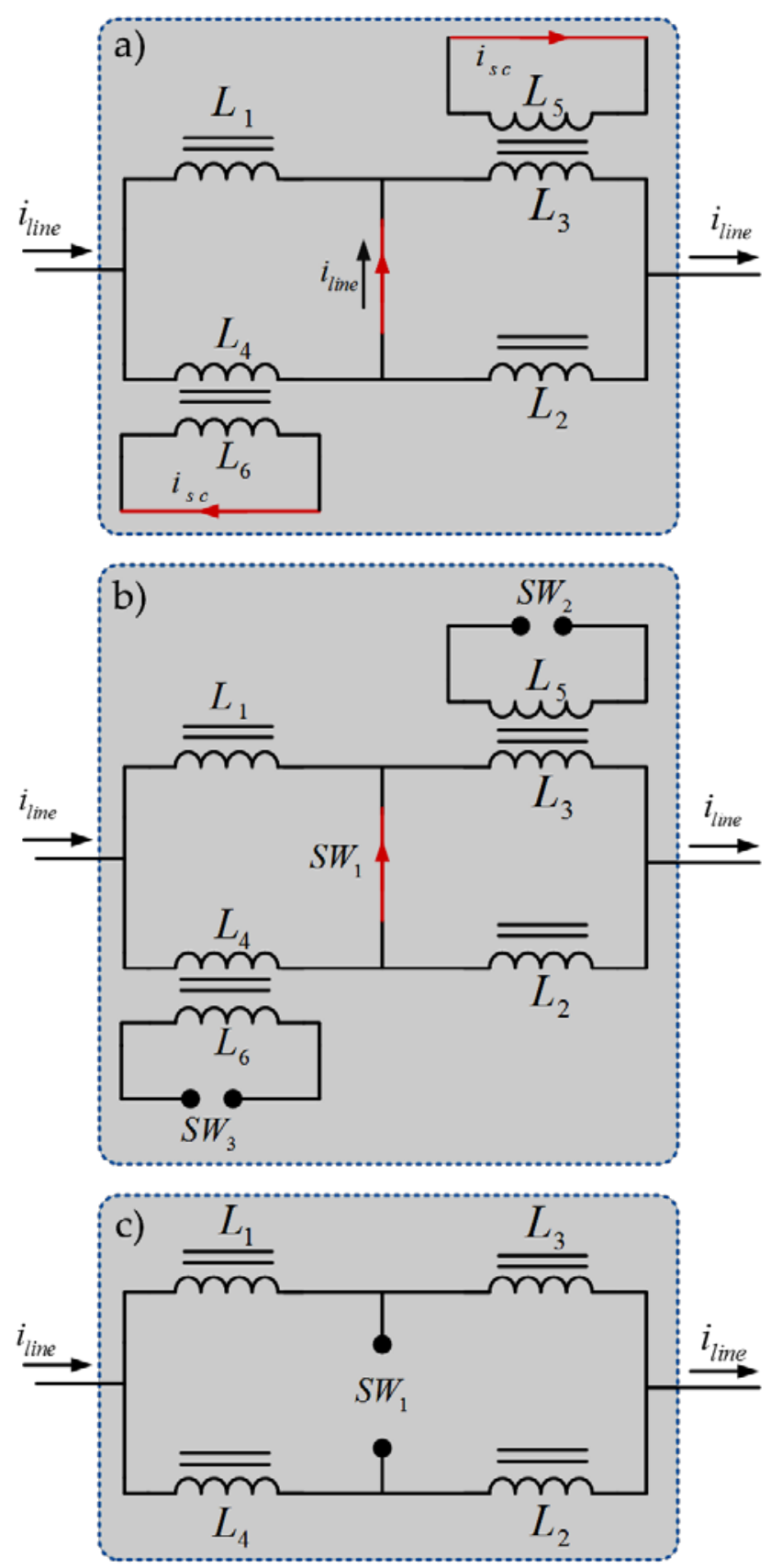

Figure 2. HBFCL equivalent circuit. (a) Normal operation mode, (b) fault operation mode in first state, and (c) fault operation mode in second state.

\subsection{Normal Operation Mode}

In this mode, as shown in Figure 2a, the secondary sides of $L_{3}$ and $L_{4}$ are short-circuited via IGBTs and the inductors are modeled by their leakage inductance and a small resistance. Considering $L_{1}$ and $L_{2}$ values, high inductive current is carried by $L_{3}, L_{4}, G_{1}$, and $G_{2}$. During the normal operation mode, all of the IGBT switches are in ON state and the maximum power flow is passed by the HBFCL.

\subsection{Pre-Limiting Mode}

After fault occurrence, the IGBTs $G_{3}$ and $G_{4}$ become turned-off and the main breaker $S W_{1}$, which includes series antiparallel switches that is shown as $G_{1}$, and $G_{2}$ change to turned-off state. In the off state of $G_{3}$ and $G_{4}$, the inductance of $L_{3}$ and $L_{4}$ increases and the current of the main switch, that is, $S W_{1}$, decreases to a low value. Figure $2 \mathrm{~b}$ shows the equivalent circuit of the pre-limiting mode. 


\subsection{Fault Current Limiting Mode}

In this mode, the current of the $S W_{1}$ decreases and it can safely be opened. In this case, the limited fault current is divided between two parallel branches, which include series connection of $L_{1}, L_{3}$ and $L_{2}, L_{4}$.

\section{Analytical Studies}

\subsection{Steady-State Mode}

Analytical studies are presented based on the three operation states of the proposed HBFCL. In the first state, there is no fault in the system. In this case, the microgrid equivalent circuit is shown in Figure $2 \mathrm{a}$ and the analytical study is done according to this circuit. In this case, the current and voltage is sinusoidal and we have the following:

$$
i_{\text {line }}=\frac{V_{S}}{Z_{S}+Z_{H B F C L}+Z_{\text {line }}+R_{\text {fault }}},
$$

where

$$
\begin{gathered}
Z_{H B F C L}=\left(r_{3}+r_{4}\right)+j\left(X_{L 3}+X_{L 4}\right), \\
V_{H B F C L}=i_{\text {line }}\left(\left(r_{3}+r_{4}\right)+j\left(X_{L 3}+X_{L 4}\right)\right),
\end{gathered}
$$

and

$$
V_{P C C}=V_{S}-i_{\text {line }}\left(\left(r_{3}+r_{4}\right)+j\left(X_{L 3}+X_{L 4}\right)+Z_{S}\right),
$$

where $V_{\mathrm{S}}, V_{\mathrm{HBFCL}}, V_{\mathrm{PCC}}$ are source voltage, HBFCL voltage drop, and voltage of point of common coupling, respectively. $i_{\text {line }}$ is line current. $L_{\mathrm{L} 3}, L_{\mathrm{L} 4}, r_{3}$, and $r_{4}$ are leakage inductances and resistances of $L_{3}$ and $L_{4}$, respectively. $Z_{s}, Z_{\text {HBFCL }}$, and $Z_{\text {line }}$ are impedances of the source, HBFCL, and line, respectively. $R_{\text {fault }}$ is resistance of the fault.

During normal operation, the power loss is calculated with Equation (5).

$$
P_{\text {loss }}=P_{C u\left(L_{3}\right)}+P_{C u\left(L_{4}\right)}+P_{C u\left(L_{5}\right)}+P_{C u\left(L_{6}\right)}+P_{S W 1}+P_{S W 2}+P_{S W 3},
$$

where

$$
\begin{gathered}
P_{C u}=i_{\text {line }}{ }^{2} \times r_{3}+i_{\text {line }}{ }^{2} \times r_{4}+i_{S c}{ }^{2} \times r_{5}+i_{s c}{ }^{2} \times r_{6}, \\
P_{S W}=i_{\text {line }} \times V_{S W 1}+2\left(i_{S c} \times V_{S W 2}\right) .
\end{gathered}
$$

The power loss depends directly on the line current, inductor secondary current, switching voltage, and coil resistance.

According to Equations (5)-(7), the HBFCL power loss is negligible by decreasing coil resistance and using the series power IGBT switch.

\subsection{Pre-Fault Limiting Mode}

In fault occurrence, $G_{3}$ and $G_{4}$ change the $H$ bridge topology and limit the fault current, and we have the following equation.

$$
X_{L 1} \times X_{L 2}=X_{L 3} \times X_{L 4}=(2 \pi f)^{2} L_{1} \times L_{2}=(2 \pi f)^{2} L_{3} \times L_{4},
$$

where $X_{L 1}$ to $X_{L 4}$ are reactor impedances while the secondary side is open-circuited and $f$ is the network frequency. 


\subsection{Fault Current Limiting Dynamic Mode}

Considering Figure 2c, we have the following equations:

$$
\begin{gathered}
2 L_{1}=L_{2}, 2 L_{4}=L_{3}, L=L_{1}=L_{4}, \\
L_{H B F C L}=\frac{\left(L_{1}+L_{3}\right)\left(L_{2}+L_{4}\right)}{\left(L_{1}+L_{3}\right)+\left(L_{2}+L_{4}\right)}=\frac{3}{2} L,
\end{gathered}
$$

and

$$
-V_{S}(t)+i_{\text {line }} r_{e q}+\left(L_{e q}\right) \frac{d i_{\text {line }}}{d t}=0
$$

and in which

$$
i_{\text {line }}(t)=A e^{-\frac{r_{e q}}{L_{e q}} t}+B V m \sin (\omega t-\theta),
$$

where $A$ and $B$ are determined based on initial condition.

$$
\begin{gathered}
r_{e q}=r_{S}+r_{\text {line }}+r_{H B F C L}+R_{\text {fault }} \\
L_{e q}=L_{S}+L_{\text {line }}+\frac{3}{2} L
\end{gathered}
$$

\section{Control Strategy}

Figure 3 shows the control system block diagram based on the proposed HBFCL.

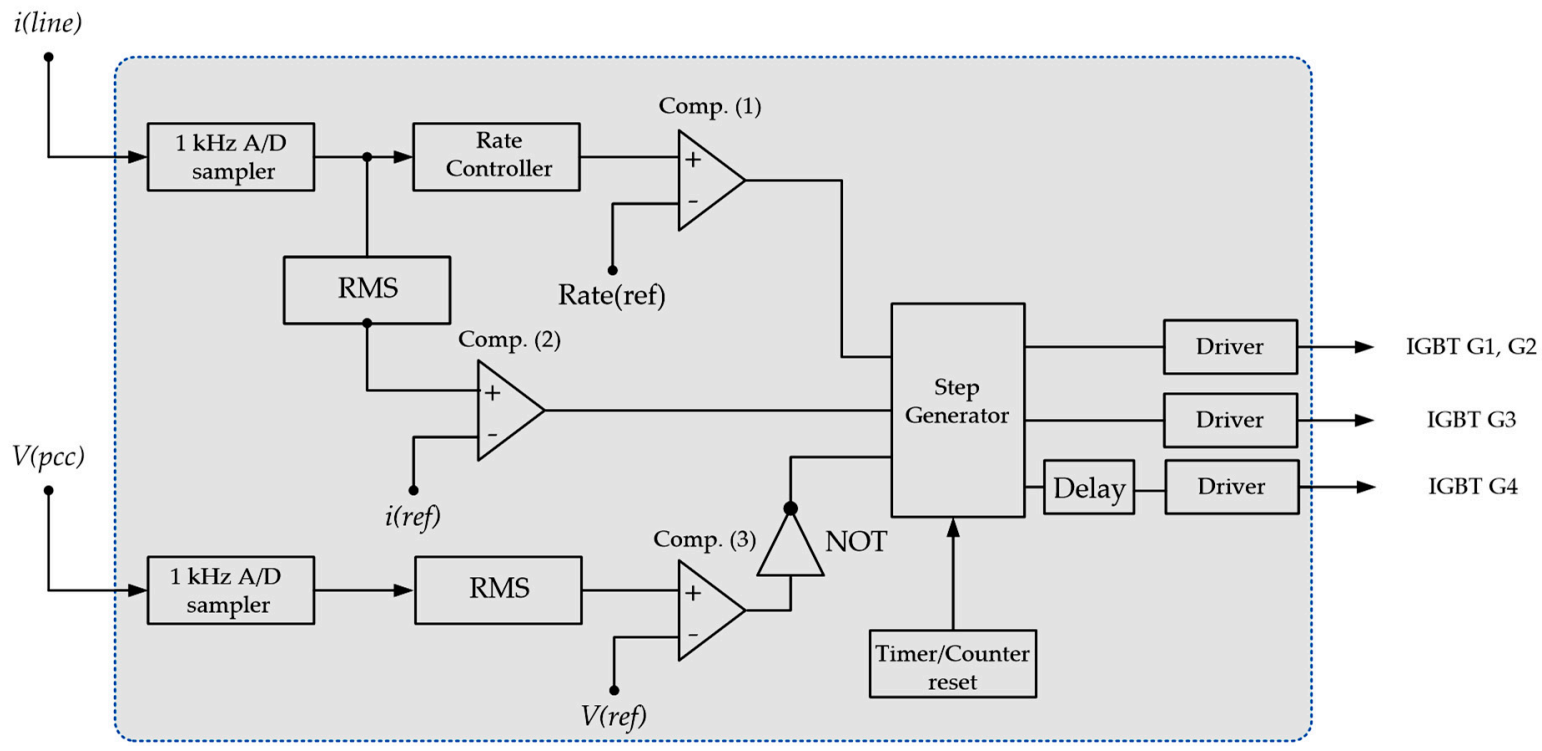

Figure 3. HBFCL control block diagram.

In this system, represented by the HBFCL control block diagram from Figure 3, the current and voltage signals are monitored via current and voltage transformers are measured and send to a digital (A/D) sampler to make the digital data. In fault cases, the current rate is raised and the rms value of the current is compared with the reference value, that is, 1.2 p.u. The voltage signal is sampled by the A/D block and its rms value is compared with the reference voltage. A step generator drives IGBT switches. The main switches are driven after a very small delay to meet the HBFCL self-protection and limit the fault current in two steps. After fault current limitation, a timer resets the step generator to turn-on $G_{1}-G_{4}$ for checking the fault clearance. 


\section{Simulation Results}

In this section, simulation results are carried out considering the system configuration shown in Figure 1. The electrical network parameters are listed in Table 1.

Table 1. The values of the $\mathrm{H}$ bridge type fault current limiter (HBFCL) parameters.

\begin{tabular}{ccc}
\hline Symbol & Description & Value \\
\hline$V_{S}$ & Source voltage & $20 \mathrm{kV}$ \\
$r_{S}$ & Source resistance & $0.1 \Omega$ \\
$r_{\text {line }}$ & Line resistance & $0.1 \Omega$ \\
$r_{f}$ & Fault resistance & $0.01 \Omega$ \\
$L_{S}$ & Source inductance & $10 \mathrm{mH}$ \\
$L_{l i n e}$ & Line inductance & $10 \mathrm{mH}$ \\
$L_{1}$ & HBFCL first inductance & $0.1 \mathrm{H}$ \\
$L_{2}$ & HBFCL second inductance & $0.2 \mathrm{H}$ \\
$L_{3}$ & HBFCL third inductance & $0.2 \mathrm{H}$ \\
$L_{4}$ & HBFCL fourth inductance & $0.1 \mathrm{H}$ \\
\hline
\end{tabular}

In order to be able to monitor the fault cases, the line to ground fault is applied to the network and the proposed HBFCL is connected in series in the line. To verify the proposed HBFCL effectiveness, two cases are considered to obtain the simulation results, that is, fault current without HBFCL effect and limited fault current with HBFCL effect, as shown in the following subsections.

\subsection{Fault Condition without HBFCL Effect}

In this section, the proposed electrical system shown in Figure 1 is simulated without the HBFCL effect. Figure 4 shows the line current provided by the main feeder during the normal and fault operation modes. During the normal operation mode, the line current amplitude is $200 \mathrm{~A}$ till $t_{1}$. After fault occurrences in $t_{1}$, the fault current is increased and its first peak amplitude reaches $6300 \mathrm{~A}$. Accordingly, if bus bar base current assumes 1000 A fault first peak is 6.1 p.u, which shows studied bus-bar high strength and high possible fault current.

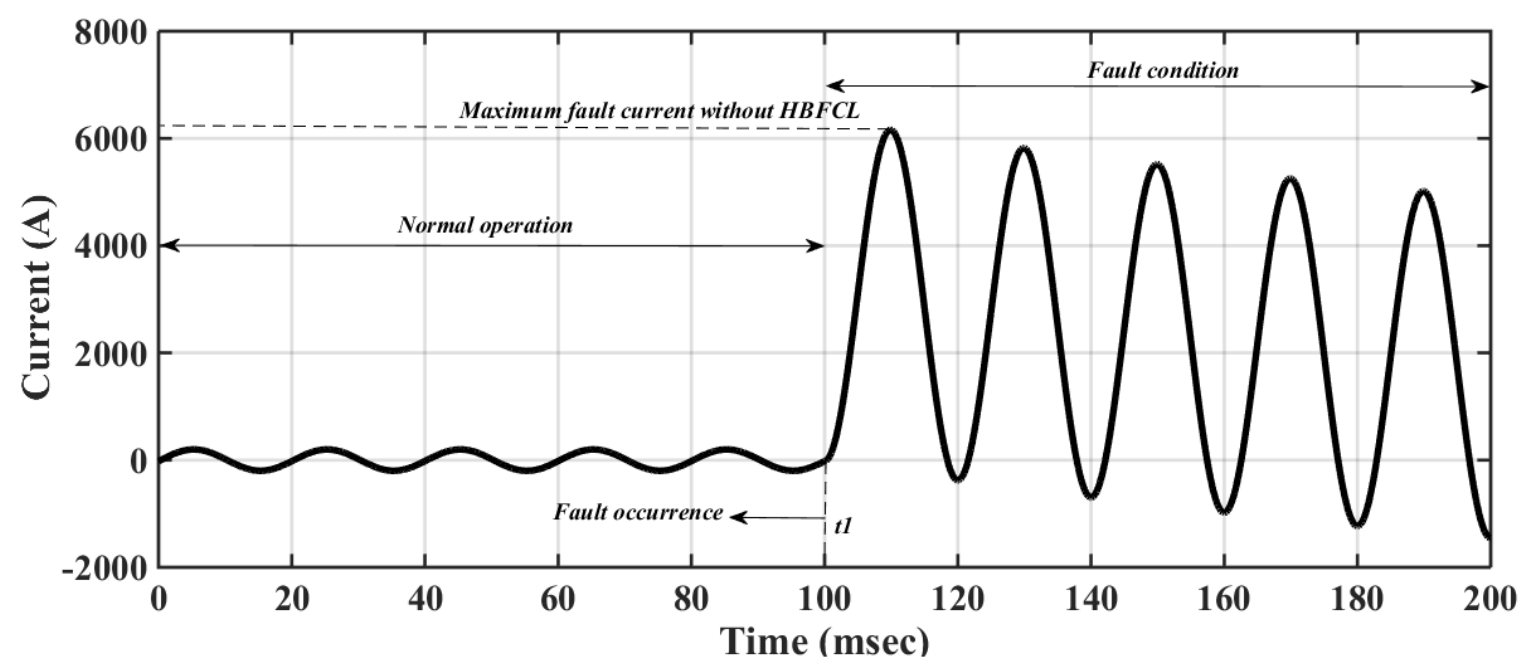

Figure 4. System voltage and current without HBFCL effect-the line current during normal and fault conditions.

As shown in Figure 5, the PCC voltage has $20 \mathrm{kV}$ amplitude during the normal operation mode, and after fault occurrences, its amplitude experiences deep voltage sag and decreases to $10 \mathrm{kV}$. 


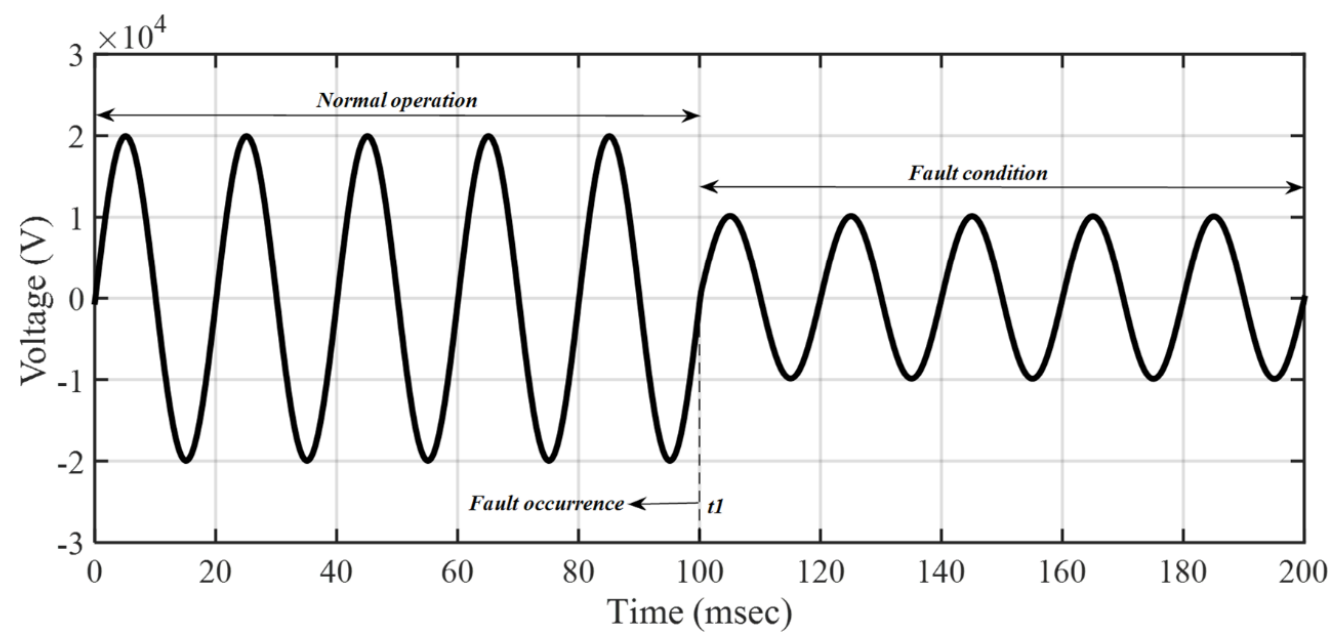

Figure 5. System voltage and current without HBFCL effect- the point of common coupling (PCC) voltage during normal and fault conditions.

\subsection{Fault Condition with HBFCL Effect}

Connecting the proposed HBFCL as a protection device to the line, the fault current is decreased to an acceptable level, as shown in Figure 6.

(a)
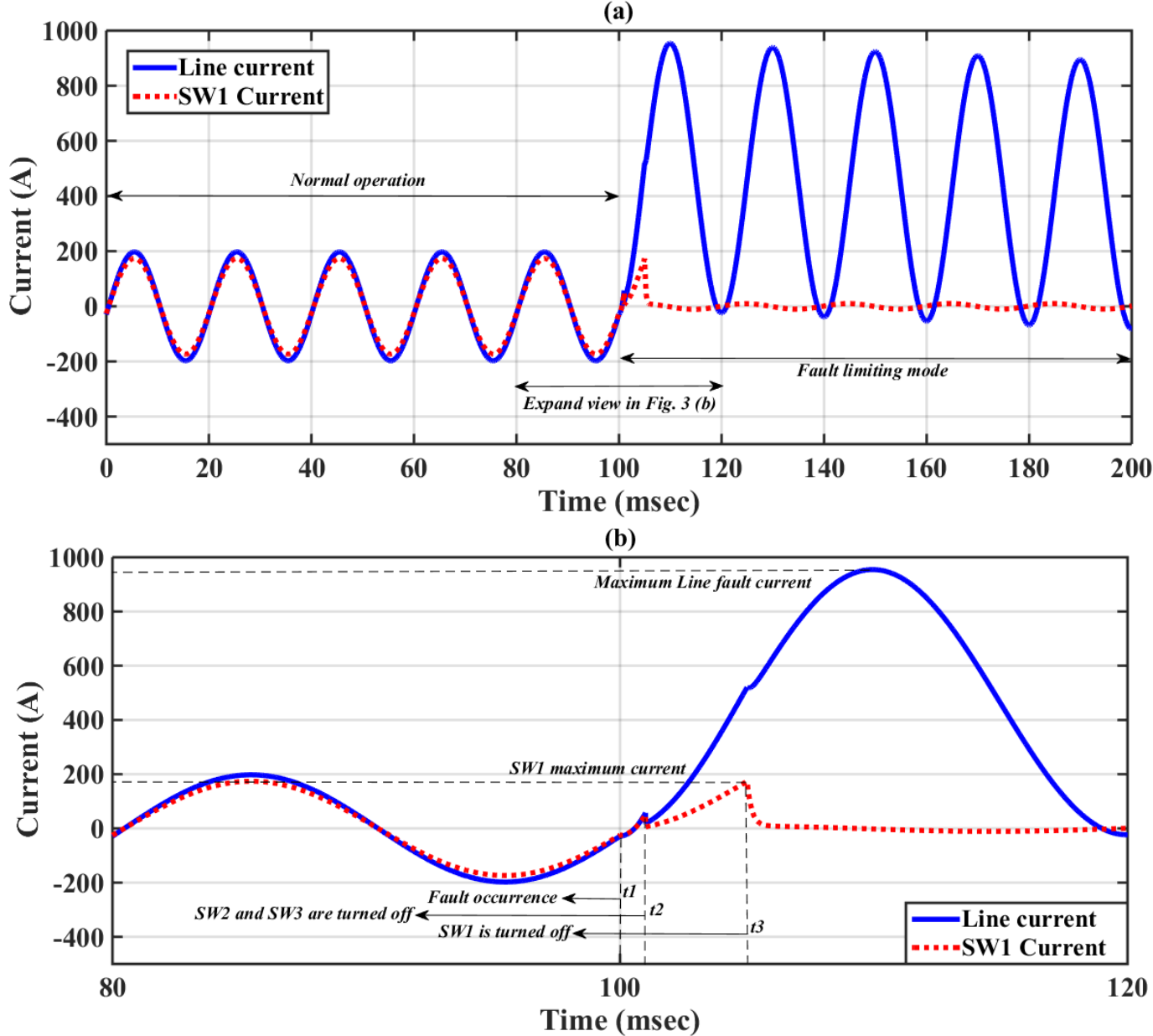

Figure 6. (a) Line and SW1 switch currents during normal and fault conditions affected by HBFCL and (b) PCC voltage during normal and fault conditions affected by HBFCL. 
In order to control the fault current, IGBTs change the HBFCL topology in two steps. In $t_{1}, 100 \mathrm{~ms}$ fault is occurred while between $t_{1}$ and $t_{2}, 102 \mathrm{~ms}$ HBFCL control system recognizes the fault but HBFCL is not operated. In $t_{2}, S W_{2}$ and $S W_{3}$ are turned off and current is limited by increasing $L_{1}$ and $L_{2}$ impedance, as shown in Figure 6a. After a small delay, the main switch $S W_{1}$ is turned off and current is decreased to nominal current. Considering the HBFCL limiting strategy, the first peak of the fault current is limited to $1 \mathrm{kA}$. Figure $6 \mathrm{~b}$ shows the PCC voltage during normal, transient, and fault states. Considering the switching transient recovery voltage (TRV) between $t_{2}$ and $t_{3}$, the TRV peak has an acceptable rate in the first switching and second switching; it is damped very well for safe switching action.

In Figure 7, it is possible to observe the $S W_{2}$ and $S W_{3}$ effect on the PCC transient recovery voltage and the $S W_{1}$ transient recovery voltage after the $100 \mathrm{~ms}$ instant, in which a transition from the normal operating mode to the fault limiting mode can be observed. This effect can also be observed in more detail in the expanded view of Figure 7.

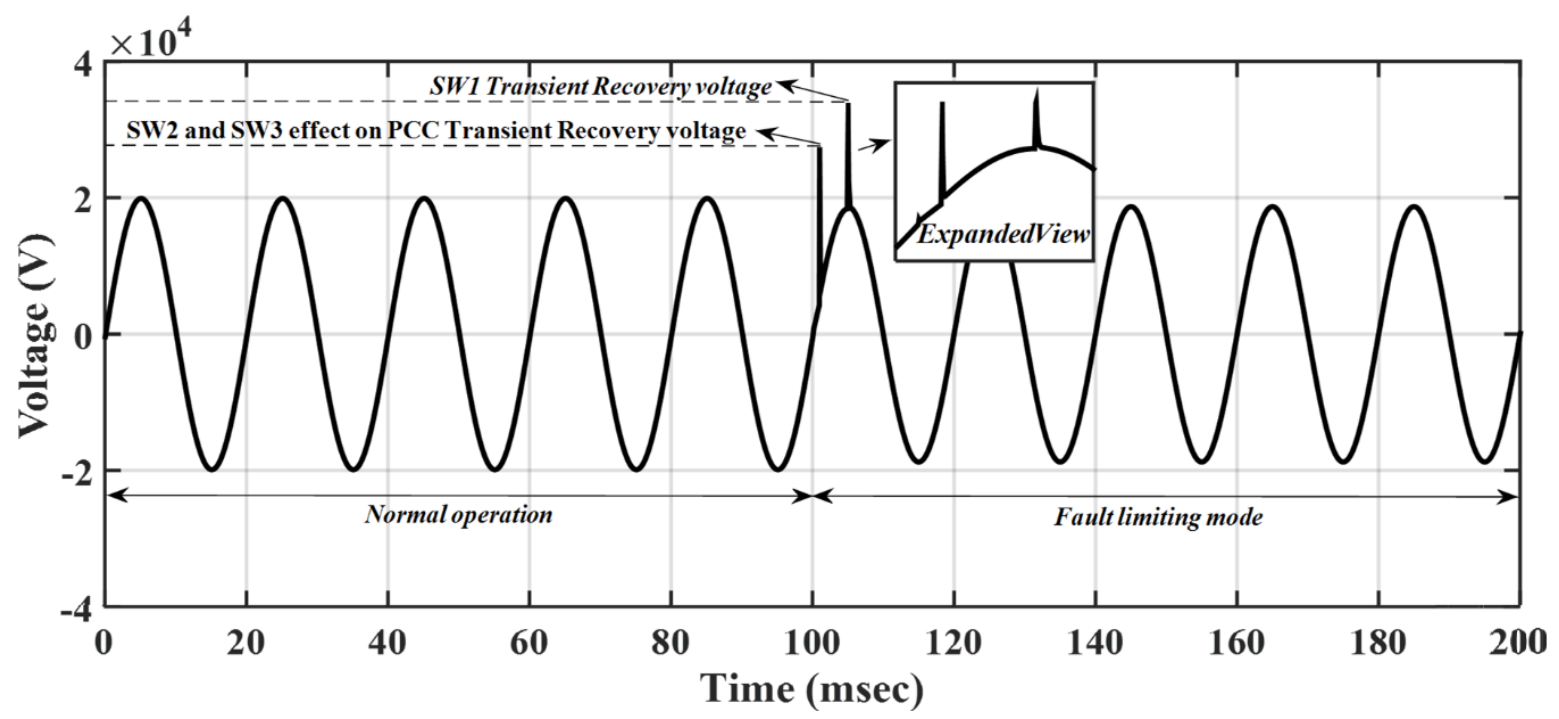

Figure 7. The effect of $S W_{2}$ and $S W_{3}$ on the PCC transient recovery voltage and the $S W_{1}$ transient recovery voltage.

Figure 8 shows the limited fault current by HBFCL where the first peak of the fault current is decreased considerably.

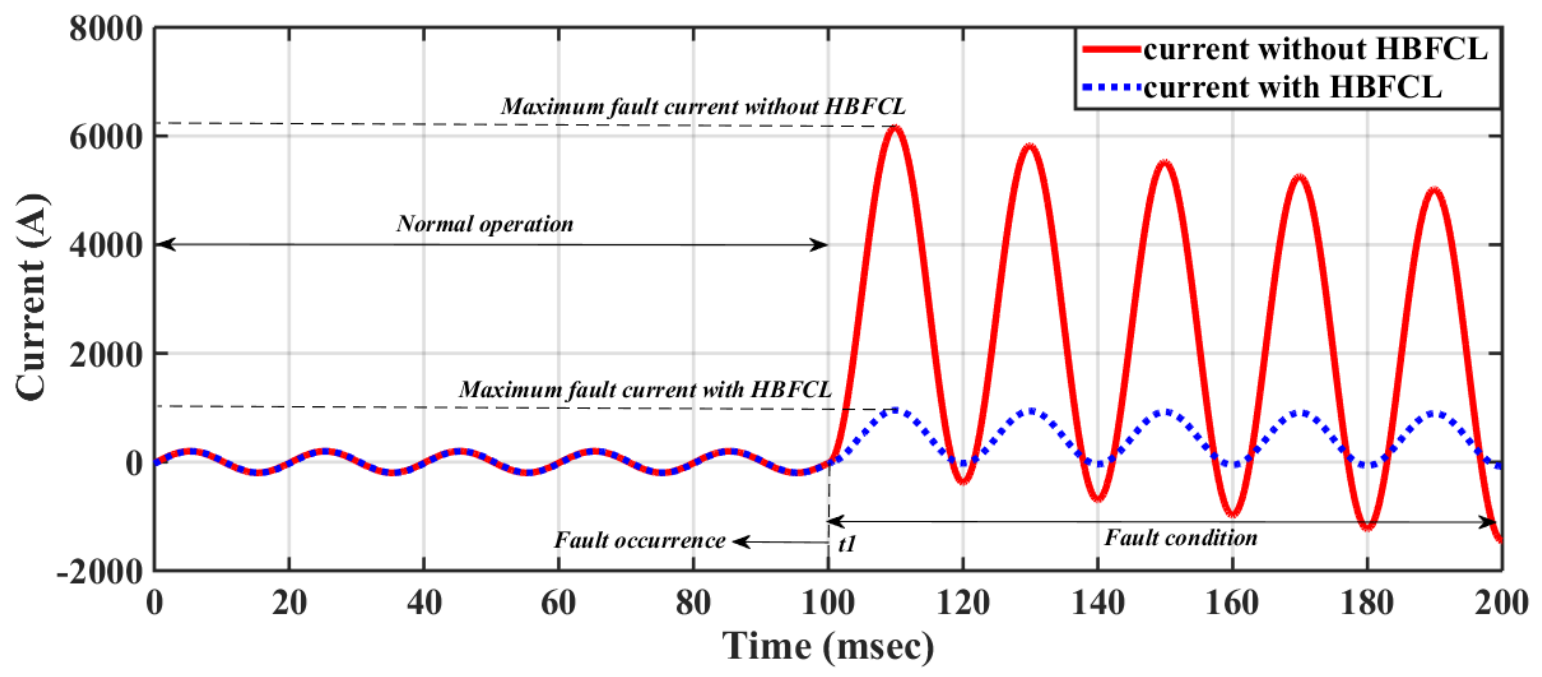

Figure 8. The line current with and without HBFCL protection. 


\section{Simulation Results}

In this section, the laboratory test prototype is built and tested to verify the simulation results. The parameters values are listed in Table 2 and the proposed prototype is shown in Figure 9.

Table 2. The values of prototype parameters.

\begin{tabular}{ccc}
\hline Symbol & Description & Value \\
\hline$V_{S}$ & Source voltage & $20 \mathrm{kV}$ \\
$r_{S}$ & Source resistance & $0.1 \Omega$ \\
$r_{\text {line }}$ & Resistance & $0.1 \Omega$ \\
$r_{f}$ & Resistance & $0.01 \Omega$ \\
$L_{S}$ & Source inductance & $10 \mathrm{mH}$ \\
$L_{\text {line }}$ & Open core 30 turns inductor & $10 \mathrm{mH}$ \\
$L_{1}$ & E-I core inductor & $0.1 \mathrm{H}$ \\
$L_{2}$ & E-I core inductor & $50 \mathrm{mH}$ \\
$L_{3}$ & E-I core inductor & $0.1 \mathrm{H}$ \\
$L_{4}$ & E-I core inductor & $0.2 \mathrm{H}$ \\
$R_{\text {load }}$ & Variable 100 W resistor & $0-100 \Omega$ \\
\hline
\end{tabular}

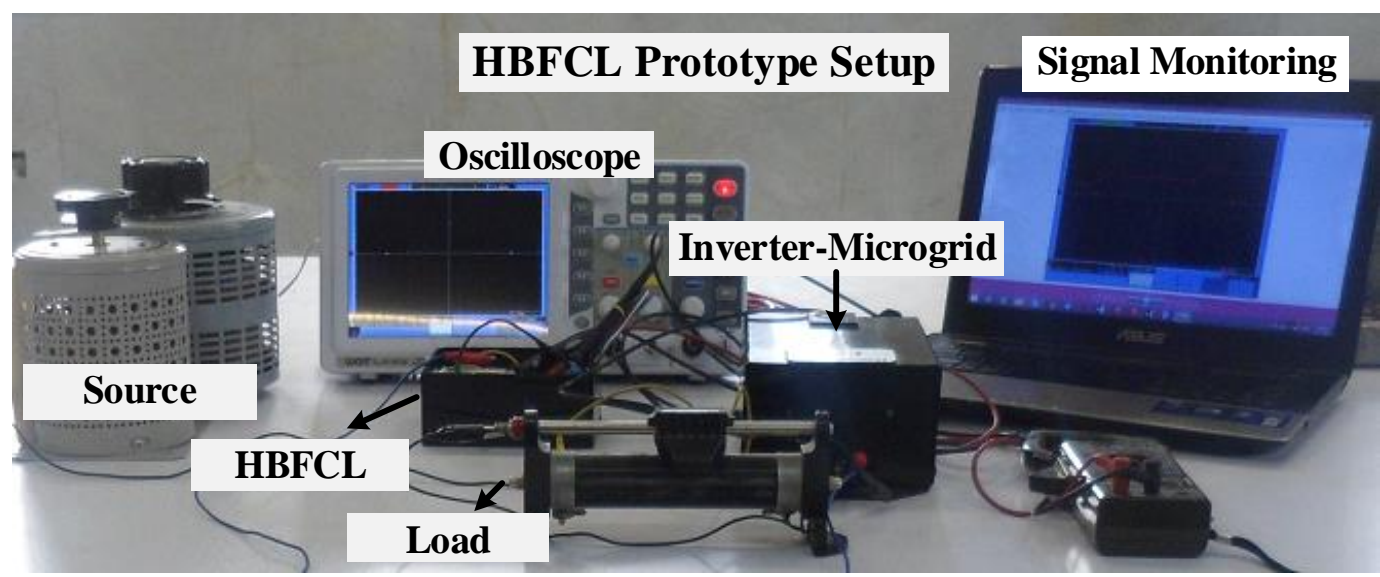

Figure 9. The proposed experimental setup.

The prototype shown in Figure 9 includes four inductors created by E-I 56 core and $0.5 \mathrm{~mm}^{2}$ wire. Core saturation has occurred in approximately $6 \mathrm{~A}$, which is out of the test range. The IGBTs with part number (STGP10NC60H) as an $S W_{1}$ and $S W_{3}$ are used in the prototype structure. The control circuit is made by NODE MCU hardware and it has independent current and voltage sensors. This hardware sends the proper pulses to IGBTs via drivers. An autotransformer is used as an electrical source and a variable resistance is used as an electrical load. The line to ground fault is applied by $25 \mathrm{~A}, 500 \mathrm{~V}$ solid-state relay.

The voltage and current signals during the normal and fault operation modes are presented in Figure 10a-c.

In Figure 10a, current waveform is shown during the normal and fault operation where the current amplitude in normal condition is $1 \mathrm{~A}$. In $t_{1}$, fault is applied to the setup and the line current raises and reaches $3 \mathrm{~A}$. This result is in fair agreement with the simulation result shown in Figure 6a. Moreover, the main switch current is measured and considered in three states, that is, normal condition, fault pre-limiting mode, and turning off the main switch. Pre-limiting operation is carried out by $\mathrm{SW}_{2}$ and $S W_{3}$ operation, which decreases the line current. The main switch is $S W_{1}$ and its operation causes safe and easy current interruption. Figure 10b shows the PCC voltage profile during the normal and fault conditions. In the normal operation, PCC voltage is $24 \mathrm{~V}$; after fault occurrences, the peak voltage reaches $40 \mathrm{~V}$. By operating the main switch, transient voltage peak value decreases to $32 \mathrm{~V}$ and, after HBFCL operation, the PCC voltage is fixed to $23 \mathrm{~V}$. This signal closely agreed with the simulation 
result shown in Figure 7. Figure 10c shows the $S W_{1}$ current in fair agreement with the simulation results shown in Figure 6b.
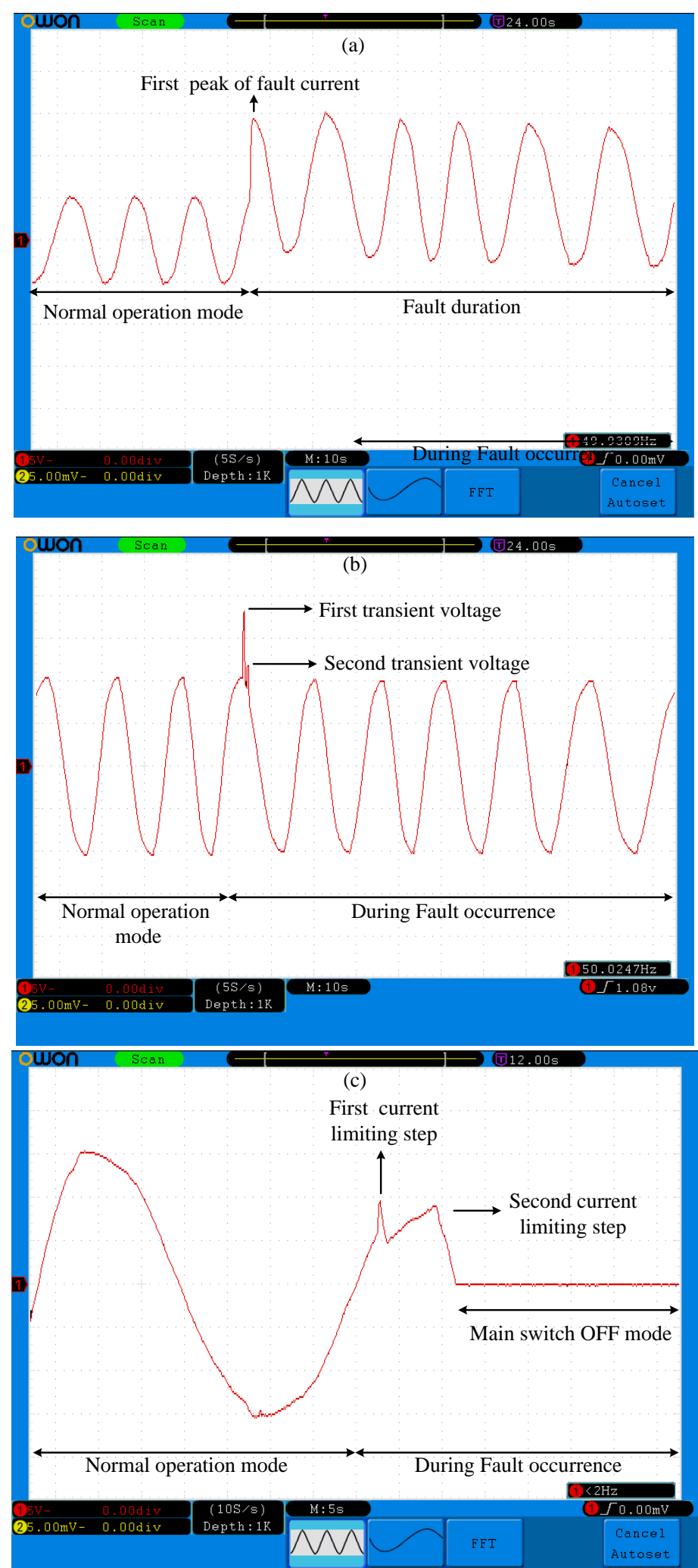

Figure 10. (a) Line current during normal and fault condition, (b) PCC voltage during normal and fault condition, and (c) main switch current during normal and fault condition. 


\section{Conclusions}

Power systems will suffer a growing pressure as a result of an upsurge in electricity demand and an increasing penetration of distributed power generation, which will cause, in turn, a higher incidence of fault current levels. Therefore, in order to mitigate such potential problems, in this paper, a new type of FCL named $\mathrm{H}$ bridge fault current limiter (HBFCL) is proposed. The simulation and experimental results show the appropriate operation of the proposed HBFCL during the normal, transient, and fault conditions. Dissipation of fault energy in the four inductors and fault current limiting by three solid-state switches are a successful method that improves performance of the HBFCL. Experimental tests validate the performed simulations in this paper. They demonstrate that the PCC voltage can be successfully protected against the TRV.

Author Contributions: Conceptualization, A.M.; Methodology, K.G.; Software, H.R.; Validation, E.P.; Writing—original draft, A.H.; Writing—review and editing, K.R.; Supervision, E.M.G.R.

Funding: This research received no external funding.

Conflicts of Interest: The authors declare no conflict of interest.

\section{References}

1. Ueda, T.; Morita, M.; Arita, H.; Kida, Y.; Kurosawa, Y.; Yamagiwa, T. Solid-sate current limiter for power distribution system. IEEE Trans. Power Deliv. 1993, 8, 1796-1801. [CrossRef]

2. Rouzbehi, K.; Zhu, J.; Zhang, W.; Gharehpetian, G.B.; Luna, A.; Rodriguez, P. Generalized voltage droop control with inertia mimicry capability-Step towards automation of multi-terminal HVDC grids. In Proceedings of the 2015 International Conference on Renewable Energy Research and Applications (ICRERA), Palermo, Italy, 22-25 November 2015; pp. 1556-1561.

3. Hoshino, T.; Salim, K.M.; Nishikawa, M.; Muta, I.; Nakamura, T. DC reactor effect on bridge type superconducting fault current limiter during load increasing. IEEE Trans. Appl. Supercond. 2001, 11, 1944-1947. [CrossRef]

4. Salim, K.M.; Hoshino, T.; Nishikawa, M.; Muta, I.; Nakamura, T. Preliminary experiments on saturated DC reactor type fault current limiter. IEEE Trans. Appl. Supercond. 2002, 12, 872-875. [CrossRef]

5. Rouzbehi, K.; Candela, J.I.; Luna, A.; Gharehpetian, G.B.; Rodriguez, P. Flexible Control of Power Flow in Multiterminal DC Grids Using DC-DC Converter. IEEE J. Emerg. Sel. Top. Power Electron. 2016, 4, 1135-1144. [CrossRef]

6. Rouzbehi, K.; Miranian, A.; Candela, J.; Luna, A.; Rodriguez, P. Instelligent voltage control in a dc micro-grid containing PV generation and energy storage. In Proceedings of the 2014 IEEE PES T\&D Conference and Exposition, Chicago, IL, USA, 14-17 April 2014; pp. 1-5.

7. Gromoll, B.; Ries, G.; Schmidt, W.; Kraemer, H.-P.; Seebacher, B.; Utz, B.; Nies, R.; Neumueller, H.-W.; Baltzer, E.; Fischer, S.; et al. Resistive fault current limiters with YBCO films $100 \mathrm{kVA}$ functional model. IEEE Trans. Appl. Supercond. 1999, 9, 656-659. [CrossRef]

8. Ye, L.; Lin, L.; Juengst, K.-P. Application Studies of Superconducting Fault Current Limiters in Electric Power Systems. IEEE Trans. Appl. Supercond. 2002, 12, 900-903.

9. Hoshino, T.; Salim, K.M.; Nishikawa, M.; Muta, I.; Nakamura, T. Proposal of saturated DC reactor type superconducting fault current limiter (SFCL). Cryogenics 2001, 41, 469-474. [CrossRef]

10. Shfaghatian, N.; Heidary, A.; Radmanesh, H.; Rouzbehi, K. Microgrids Interconnection to Upstream AC grid Using a Dual-function Fault Current Limiter and Power Flow Controller: principle and test results. IET Energy Syst. Integr. 2019. [CrossRef]

11. Heidary, A.; Radmanesh, H.; Bakhshi, A.; Rouzbehi, K.; Pouresmaeil, E. A Compound Current Limiter and Circuit Breaker. Electronics 2019, 5, 551. [CrossRef]

12. Radmanesh, H.; Heidary, A.; Fathi, S.H.; Gharehpetian, G.B. Dual Function Ferroresonance and Fault Current Limiter Based on DC Reactor. IET Gener. Transm. Distrib. 2016, 10, 2058-2065. [CrossRef]

13. Radmanesh, H.; Fathi, S.H.; Gharehpetian, G.B.; Heidary, A. Bridge-Type Solid-State Fault Current Limiter Based on AC/DC Reactor. IEEE Trans. Power Deliv. 2016, 31, 200-209. [CrossRef] 
14. Heidary, A.; Radmanesh, H.; Fathi, S.H.; Khamse, H.R.R. Improving Transient Recovery voltage of circuit breaker using Fault Current Limiter. Res. J. Appl. Sci. Eng. Technol. 2012, 4, 5123-5128.

15. Naderi, S.B.; Jafari, M.; Hagh, M.T. Parallel-Resonance-Type Fault Current Limiter. IEEE Trans. Ind. Electron. 2013, 60, 2538-2546. [CrossRef]

16. Heidary, A.; Radmanesh, H.; Fathi, H.; Gharehpetian, G.B. Series transformer based diode-bridge-type solid state fault current limiter. Front. Inf. Technol. Electron. Eng. 2015, 16, 769-784. [CrossRef]

17. Yamaguchi, H.; Kataoka, T. An Experimental Investigation of Magnetic Saturation of a Transformer Type Superconducting Fault Current Limiter. IEEE Trans. Appl. Supercond. 2009, 19, 1876-1879. [CrossRef]

18. Kcilin, V.; Kovalcv, I.; Kmglov, S.; Stepanov, V.; Slmgaev, I.; Shchcrbzkov, V. Model of HTS Three-phase Saturated Core Fault Current Limiter. IEEE Trans. Appl. Supercond. 2000, 10, 836-839.

19. Moscrop, J.W. Experimental Analysis of the Magnetic Flux Characteristics of Saturated Core Fault Current Limiters. IEEE Trans. Magn. 2013, 49, 874-882. [CrossRef]

20. Commins, P.A.; Moscrop, J.W. Three Phase Saturated Core Fault Current Limiter Performance with a Floating Neutral. In Proceedings of the IEEE Electrical Power and Energy Conference, London, ON, Canada, 10-12 October 2012; pp. 249-254.

21. Chen, X.; Chen, B.; Tian, C.; Yuan, J.; Liu, Y. Modeling and Harmonic Optimization of a Two-Stage Saturable Magnetically Controlled Reactor for an Arc Suppression Coil. IEEE Trans. Ind. Electron. 2012, 59, 2824-2831. [CrossRef]

22. Moriconi, F.; de la Rosa, F.; Darmann, F.; Nelson, A.; Masur, L. Deployment of Saturated-Core Fault Current Limiters in Distribution and Transmission Substations. IEEE Trans. Appl. Supercond. 2011, 21, 1288-1293. [CrossRef]

23. Xin, Y.; Gong, W.Z.; Niu, X.Y.; Gao, Y.Q.; Guo, Q.Q.; Xiao, L.X.; Cao, Z.J.; Hong, H.; Wu, A.G.; Li, Z.H.; et al. Manufacturing and Test of a 35 kV/90 MVA Saturated Iron-Core Type Superconductive Fault Current Limiter for Live-Grid Operation. IEEE Trans. Appl. Supercond. 2009, 19, 1934-1937. [CrossRef]

24. Xin, Y.; Hong, H.; Wang, J.Z.; Gong, W.Z.; Zhang, J.Y.; Ren, A.L.; Zi, M.R.; Xiong, Z.Q.; Si, D.J.; Ye, F. Performance of the $35 \mathrm{kV} / 90$ MVA SFCL in Live-Grid Fault Current Limiting Tests. IEEE Trans. Appl. Supercond. 2011, 21, 1294-1297. [CrossRef]

25. Zheng, F.; Deng, C.; Chen, L.; Li, S.; Liu, Y.; Liao, Y. Transient Performance Improvement of Micro-grid by a Resistive Superconducting Fault Current Limiter. IEEE Trans. Appl. Supercond. 2015, 25. [CrossRef]

26. Hwang, J.-S.; Khan, U.A.; Shin, W.-J.; Seong, J.-K.; Lee, J.-G.; Kim, Y.; Lee, B.-W. Validity Analysis on the Positioning of Superconducting Fault Current Limiter in Neighboring AC and DC Microgrid. IEEE Trans. Appl. Supercond. 2013, 23. [CrossRef]

27. Abdolkarimzadeh, M.; Nazari-Heris, M.; Abapour, M.; Sabahi, M. A Bridge Type Fault Current Limiter for Energy Management of AC/DC Microgrids. IEEE Trans. Power Electron. 2017, 32, 9043-9050. [CrossRef]

28. Heidary, A.; Radmanesh, H.; Rouzbehi, K.; Pou, J. A DC-Reactor Based Solid-State Fault Current Limiter for HVDC Applications. IEEE Trans. Power Deliv. 2019, 34, 720-728. [CrossRef]

29. Eladawy, M.; Metwally, I.A. A Novel Five-Leg Design for Performance Improvement of Three-Phase Presaturated Core Fault-Current Limiter. IEEE Trans. Magn. 2018, 54. [CrossRef]

30. Yan, S.; Tang, Y.; Ren, L.; Xu, Y.; Wang, Z.; Liang, S.; Zhang, Z. Design and Verification Test of a Flux-Coupling-Type Superconducting Fault Current Limiter. IEEE Trans. Magn. 2018, 54. [CrossRef]

31. Tseng, H.-T.; Jiang, We.; Lai, J. A Modified Bridge Switch-Type Flux-Coupling Non-superconducting Fault Current Limiter for Suppression of Fault Transients. IEEE Trans. Power Deliv. 2018, 33, 2624-2633. [CrossRef]

(C) 2019 by the authors. Licensee MDPI, Basel, Switzerland. This article is an open access article distributed under the terms and conditions of the Creative Commons Attribution (CC BY) license (http://creativecommons.org/licenses/by/4.0/). 